\title{
Influence of Heating Temperature on Interface Separation Behavior between Ti-20 mol\% Al Alloy and High Carbon Steel
}

\author{
Yasuhiro Morizono ${ }^{1}$, Yoshikazu Kodama ${ }^{1, *}$, Takateru Yamamuro ${ }^{2}$ and Minoru Nishida ${ }^{3}$ \\ ${ }^{1}$ Department of Materials Science and Engineering, Graduate School of Science and Technology, \\ Kumamoto University, Kumamoto 860-8555, Japan \\ ${ }^{2}$ Technical Division, Faculty of Engineering, Kumamoto University, Kumamoto 860-8555, Japan \\ ${ }^{3}$ Department of Applied Science for Electronics and Materials, Interdisciplinary Graduate School of Engineering Sciences, \\ Kyushu University, Kasuga 816-8580, Japan
}

$\mathrm{Ti}-20 \mathrm{~mol} \% \mathrm{Al}(\mathrm{Ti}-12.3$ mass $\% \mathrm{Al})$ alloy was diffusion-bonded to high carbon steel $(0.82 \mathrm{mass} \% \mathrm{C})$ at $1273 \mathrm{~K}$ for $3.6 \mathrm{ks}$ in a vacuum. The joint had a space of a few micrometers in thickness between the Ti-20 mol\% Al alloy and the steel, and several specimens separated near the interface promptly after the bonding treatment. This phenomenon is referred to as 'interface separation'. This paper describes the influence of heating temperature on the interface separation. Diffusion bonding of the Ti-20 mol\% Al alloy to the high carbon steel was carried out at 1173 to $1423 \mathrm{~K}$ for 0.9 to $3.6 \mathrm{ks}$ in a vacuum, and then several joints were heated at a given temperature for up to $176.4 \mathrm{ks}$ in an evacuated silica tube. At $1173 \mathrm{~K}$, the separation phenomenon could not be confirmed even after prolonged heat treatment. This joint had four kinds of reaction regions in the vicinity of the interface, and their thicknesses increased in proportion to square root of holding time. On the other hand, the joint bonded at more than $1273 \mathrm{~K}$ showed the separation at the interface. As the heating temperature increased, the holding time required to induce the phenomenon became shorter. To clarify a time when the separation occurs in the diffusion bonding process, the joint with a special shape was prepared and quenched into the water from $1273 \mathrm{~K}$. The generation of voids was recognized at the interface. These results suggest that the occurrence of the interface separation is associated with interdiffusion between the Ti-20 mol\% $\mathrm{Al}$ alloy and the steel. [doi:10.2320/matertrans.M2009035]

(Received January 30, 2009; Accepted May 7, 2009; Published July 1, 2009)

Keywords: Ti-20 mol\%Al alloy, high carbon steel, diffusion bonding, interface separation, void

\section{Introduction}

Titanium aluminides, which are typified by $\mathrm{Ti}_{3} \mathrm{Al}$ and $\mathrm{TiAl}$, are usable as high temperature structural materials in the aerospace and automobile industries, because they have a low density and a high strength at elevated temperatures. They have been joined to themselves and other materials by various bonding methods to encourage their effective utilization. The authors have previously investigated the interfacial microstructures and the bonding strength of Ti-Al alloy/steel joints, ${ }^{1-3)}$ since the steel is a dominant structural material in industrial products. In these studies, Ti-20 mol\% Al (Ti-20Al, i.e. Ti-12.3 mass\% Al) alloy was diffusionbonded to high carbon steel $(0.82$ mass $\% \mathrm{C})$ at $1273 \mathrm{~K}$ for $3.6 \mathrm{ks}$ in a vacuum. Although the obtained joint deceptively retained a bonding state, there was a space between the Ti$20 \mathrm{Al}$ alloy and the steel. Several specimens also separated near the interface promptly after the bonding treatment. We refer to this phenomenon as "interface separation". This is found to depend on alloy composition, carbon content in the used iron materials and bonding (heating) condition. Consequently, the Ti-20Al/high carbon steel joint bonded at $1073 \mathrm{~K}$ for $3.6 \mathrm{ks}$ had a bonding strength of $166 \mathrm{MPa}^{2}$

It is considered that the interface separation is attributed to preferential diffusion of $\mathrm{Fe}$ into the Ti-20Al alloy, which transforms from a $\mathrm{Ti}(\alpha)+\mathrm{Ti}_{3} \mathrm{Al}\left(\alpha_{2}\right)$ duplex structure to an $\alpha$ single phase structure at about $1273 \mathrm{~K}^{2,3)}$ To evidence this proposition, we have to clarify a time when the separation occurs in the bonding treatment. If the Ti-20Al alloy removes from the steel on a cooling step from the heating temperature,

*Graduate Student, Kumamoto University. Present address: Kyocera Corporation, Satsumasendai 895-0292, Japan the influence of thermal stress and reaction products is considered as a cause of the separation. Meanwhile, if the destruction arises at the interface in a holding step at the heating temperature, interdiffusion across the interface is a dominant factor for the separation phenomenon.

In the present study, diffusion bonding of the Ti-20Al alloy to the high carbon steel was carried out at a wider temperature range of 1173 to $1423 \mathrm{~K}$. If the separation occurs in the holding step in the bonding treatment, it is expected that the growth of reaction regions in the obtained joint has no connection with the heating temperature due to the inhibition of the diffusion of constituent elements. In addition, the joint with a special shape was prepared to quench into the water from the high-temperature region, and its microstructural aspect was investigated.

\section{Experimental Procedure}

Ti-Al binary alloy containing $20 \mathrm{~mol} \% \mathrm{Al}$ (12.3 mass\% $\mathrm{Al})$ was produced by using an arc melting process. The obtained ingot was homogenized at $1273 \mathrm{~K}$ for $86.4 \mathrm{ks}$ in a vacuum of less than $3 \mathrm{mPa}$. Commercially produced carbon steel, which contained 0.82 mass $\%$ C, 0.18 mass $\% \mathrm{Si}, 0.40$ mass $\% \mathrm{Mn}$, 0.013 mass $\% \quad \mathrm{P}, \quad 0.021$ mass $\% \quad \mathrm{~S}, \quad 0.10$ mass $\% \quad \mathrm{Cr}$ and 0.08 mass $\% \mathrm{Cu}$, specified as SK5 tool steel by the Japan Industrial Standards, was used as a mating material for the Ti-20Al alloy. The Ti-20Al alloy and the steel were machined into a rectangular block with dimensions of $5 \mathrm{~mm} \times 5 \mathrm{~mm} \times 3 \mathrm{~mm}$. The Ti-20Al alloy plate with a thickness of $0.3 \mathrm{~mm}$ was also prepared. These bonding surfaces were finished with \#1200 emery paper. Before bonding treatment, the specimens were degreased in acetone using an ultrasonic cleaner and dried with hot air. 
(a)

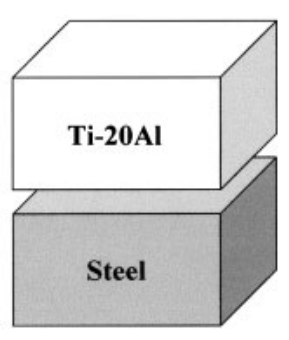

(b)

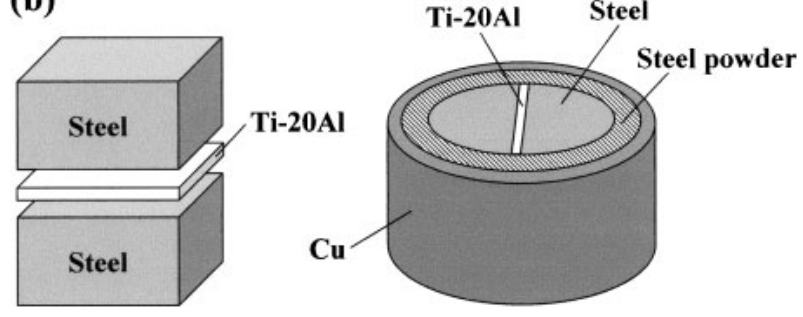

Fig. 1 Configurations of bonding couples. (a) Normal specimen. (b) Specimen for quenching from $1273 \mathrm{~K}$.

The Ti-20Al alloy was stacked on the steel as shown in Fig. 1(a). This couple was fixed in a jig consisting of two molybdenum rods and two austenitic stainless steel blocks, and heated in the range from 1173 to $1423 \mathrm{~K}$ for 0.9 to $3.6 \mathrm{ks}$ in a vacuum of less than $3 \mathrm{mPa}$. The heating rate up to these temperatures was $0.17 \mathrm{~K} / \mathrm{s}$. Subsequently, several couples were heated at a given temperature for up to $176.4 \mathrm{ks}$ in an evacuated silica tube. All specimens were cooled in the furnace to room temperature after a holding step in these treatments.

To investigate microstructural aspects at elevated temperatures, the specimen for water-quenching was also fabricated. Its configuration is presented in Fig. 1(b). The Ti-20Al alloy plate was inserted between two steel blocks, and this couple was heated at $1173 \mathrm{~K}$ for $0.9 \mathrm{ks}$ in a vacuum. The obtained joint was carefully machined into a columnar shape of $4 \mathrm{~mm}$ in diameter and $5 \mathrm{~mm}$ in height, and then packaged within a copper pipe. A space between the joint and the pipe was filled up with high carbon steel powder. It is expected that the introduction of cracks at the interface due to water-quenching can be avoided by coating the joint with the sintered steel powder. This assembly was heated at $1273 \mathrm{~K}$ for $0.9 \mathrm{ks}$ in the evacuated silica tube and immediately quenched into the water.

The specimens were mounted in polyester resin and cut perpendicular to the interface to reveal the microstructures. When the Ti-20Al alloy already separated from the steel at the time of removing from the electric furnace, both materials were reintegrated into the shape of the joint and fixed in the resin. The cross sections were ground with emery papers and then finished with alumina powder. After etching, they were examined by using an optical microscope and a scanning electron microscope (SEM) equipped with an energy dispersive X-ray spectroscope (EDX).

\section{Results and Discussion}

\subsection{Interfacial microstructures at $1173 \mathrm{~K}$}

Figures 2(a) and 2(b) show SEM micrographs of the interface in the Ti-20Al alloy/high carbon steel joint bonded at $1173 \mathrm{~K}$ for $3.6 \mathrm{ks}$. Several reaction products were observed in the vicinity of the interface. This joint was also heat-treated at $1173 \mathrm{~K}$ for up to $176.4 \mathrm{ks}$, and the interfacial microstructures were shown in Figs. 2(c) and 2(d). In these figures, total holding time of the bonding and heat treatments is 90 and $180 \mathrm{ks}$, respectively. Four reaction regions indicated as I to IV were confirmed around the interface. To identify the reaction products and layers in regions I to IV, their composition ratios of $\mathrm{Ti}, \mathrm{Al}$ and $\mathrm{Fe}$ were measured by using SEM-EDX. Table 1 shows the results of the composition analysis. Region I was located in the Ti-20Al alloy and had needle-shaped products. From the results in

Table 1 Chemical compositions of reaction products in regions I to IV shown in Fig. 2.

\begin{tabular}{crcr}
\hline \multirow{2}{*}{ Resion } & \multicolumn{3}{c}{ Analytical compositon $(\mathrm{mol} \%)$} \\
\cline { 2 - 4 } & $\mathrm{Ti}$ & $\mathrm{Al}$ & $\mathrm{Fe}$ \\
\hline I & 78.7 & 8.3 & 13.0 \\
II & 66.4 & 29.1 & 4.5 \\
III & 98.6 & 0.2 & 1.2 \\
IV & 0.2 & 0.1 & 99.7 \\
\hline
\end{tabular}
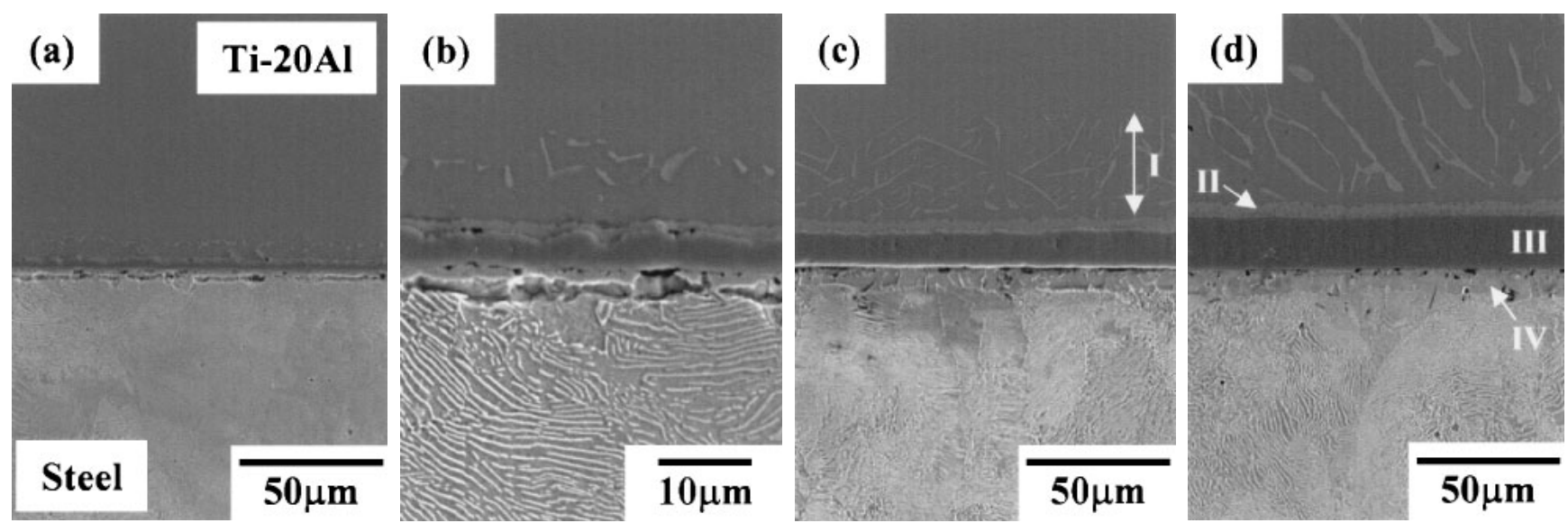

Fig. 2 SEM micrographs of the interface in Ti-20Al alloy/high carbon steel joint bonded at $1173 \mathrm{~K}$ for $3.6 \mathrm{ks}$. (a) and (b) As-bonded. (b) After heat treatment at $1173 \mathrm{~K}$ for $86.4 \mathrm{ks}$. (c) After heat treatment at $1173 \mathrm{~K}$ for $176.4 \mathrm{ks}$. 


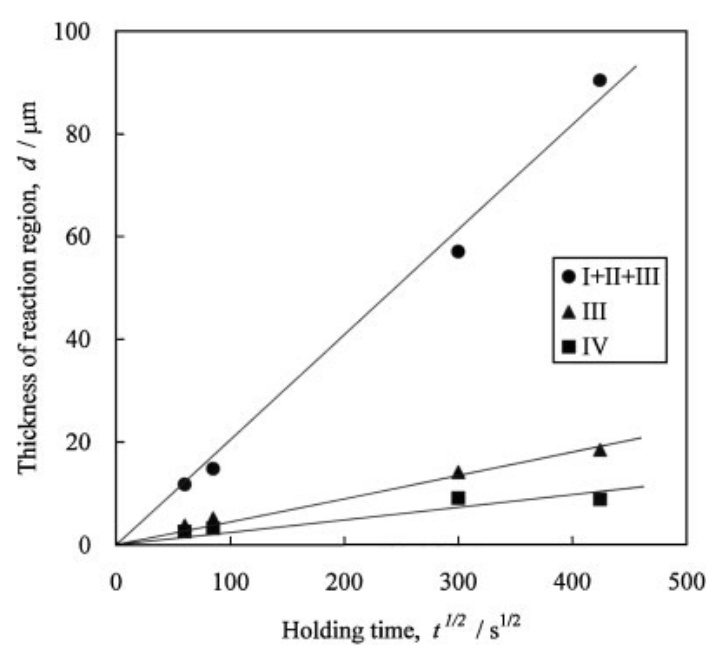

Fig. 3 Relationship between holding time and thickness of regions I to IV shown in Fig. 2. Ti-20Al alloy/high carbon steel joint was fabricated at $1173 \mathrm{~K}$ for $3.6 \mathrm{ks}$ and then heat-treated at $1173 \mathrm{~K}$ for up to $176.4 \mathrm{ks}$. Horizontal axis represents square root of total holding time of bonding and heat treatments.

Table 1, the products are considered to be formed by the diffusion of $\mathrm{Fe}$ into the Ti-20Al alloy. Fe was also detected in the reaction layer indicated by II, and its content was lower than that in the needle-shape products in region I. Region III had a continuous layer along the interface between the Ti-20Al alloy and the steel. Since the composition ratio of $\mathrm{Ti}$ was the highest in this region, it is thought that $\mathrm{TiC}$ was formed by the reaction with $\mathrm{C}$ in the steel. In region IV, Fe was a dominant element. The formation of the $\mathrm{TiC}$ layer in region III has a possibility to lead to decarburization of the steel in region IV. In addition, $\mathrm{Ti}$ and $\mathrm{Al}$, which are known to be ferrite stabilizers, diffused into the decarburization region. Therefore, region IV was identified as a ferrite phase.

The configuration of the interfacial microstructures in Fig. 2 was well accorded with our previous report. ${ }^{3)}$ In addition, it should be noted that the interface separation described above was not induced in the Ti-20Al alloy/high carbon steel joint bonded at $1173 \mathrm{~K}$. Figure 3 shows the relationship between the holding time and the thickness of regions I to IV in the joint bonded at $1173 \mathrm{~K}$. The horizontal axis represents square root of total holding time of the bonding and heat treatments. Furthermore, the thickness expressed by "I + II + III" corresponds to the diffusion distance of $\mathrm{Fe}$ into the Ti-20Al alloy, since it is thought by previous research ${ }^{2,3)}$ that the initial interface is located between regions III and IV in Fig. 2. The growth of each region showed the linear relationship for square root of the holding time. This means that the Ti-20Al alloy is attached firmly to the steel at a heating temperature of $1173 \mathrm{~K}$ and the diffusion of constituent elements is retained even after the prolonged heat treatment.

\subsection{Interfacial microstructures at a heating temper- ature of more than $1273 \mathrm{~K}$}

Figure 4 shows SEM micrographs of the interface in the Ti-20Al alloy/high carbon steel joint bonded at $1273 \mathrm{~K}$. The holding time in Figs. 4(a) and 4(b) is 0.9 and $1.8 \mathrm{ks}$,
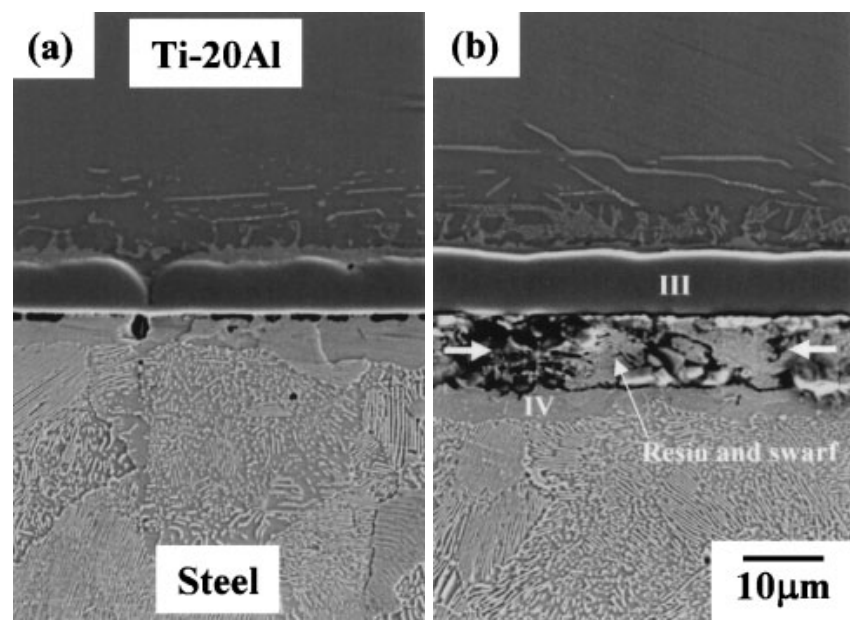

Fig. 4 SEM micrographs of the interface in Ti-20Al alloy/high carbon steel joint bonded at $1273 \mathrm{~K}$ for (a) 0.9 and (b) $1.8 \mathrm{ks}$.

respectively. These interfacial microstructures were approximately equal to those in Fig. 2 and, thus, regions III and IV in Fig. 4(b) were identified as $\mathrm{TiC}$ and ferrite layers, respectively. The products, which were formed by the diffusion of Fe into the Ti-20Al alloy, were also observed.

In Fig. 4(a), the shape of the joint was kept after the bonding treatment. However, the joint bonded at $1273 \mathrm{~K}$ for $1.8 \mathrm{ks}$ broke in the vicinity of the interface and showed the separation phenomenon, as shown in Fig. 4(b). The fracture position was between regions III and IV. Some dust such as resin and grinding swarf lodged in this position, since the Ti-20Al alloy and the steel were restored to the shape of the joint after the bonding treatment. The interface separation was also recognized in the joint bonded at $1273 \mathrm{~K}$ for $3.6 \mathrm{ks}^{2,3)}$ As compared to Fig. 2, the bonding treatment was conducted with the same heating and cooling rates, whereas only the heating temperature was different. Considering the dependency on the holding time at $1273 \mathrm{~K}$, it seems that the thermal stress occurring in the bonding process has little influence on the interface separation. On the other hand, it is noteworthy that there were voids along the interface in Fig. 4(a). Although the formation of the voids is likely to be affected by polishing and etching for microstructure observations, these existences may be closely connected with the interface separation behavior.

The interfacial microstructure of the joint bonded at $1323 \mathrm{~K}$ for $0.9 \mathrm{ks}$ is presented in Fig. 5. Two white arrows in the figure indicate the position of the space. The holding time required to induce the interface separation was shorter than the case in Fig. 4.

Figure 6 shows the relationship between the heating temperature and the thickness of reaction regions in the Ti$20 \mathrm{Al}$ alloy/high carbon steel joint bonded at 1173 to $1423 \mathrm{~K}$ for $3.6 \mathrm{ks}$. Regions I to IV in the figure correspond to those in Fig. 2, and the region expressed by "I + II + III" means the diffusion distance of $\mathrm{Fe}$ into the Ti-20Al alloy as already mentioned. In the $\mathrm{TiC}$ layer in region III, the thickness appears to become slightly thin with an increase in the heating temperature. The ferrite layer in region IV also denoted the same tendency. If the diffusion proceeds during the bonding treatment, the $\mathrm{TiC}$ and ferrite layers should be 


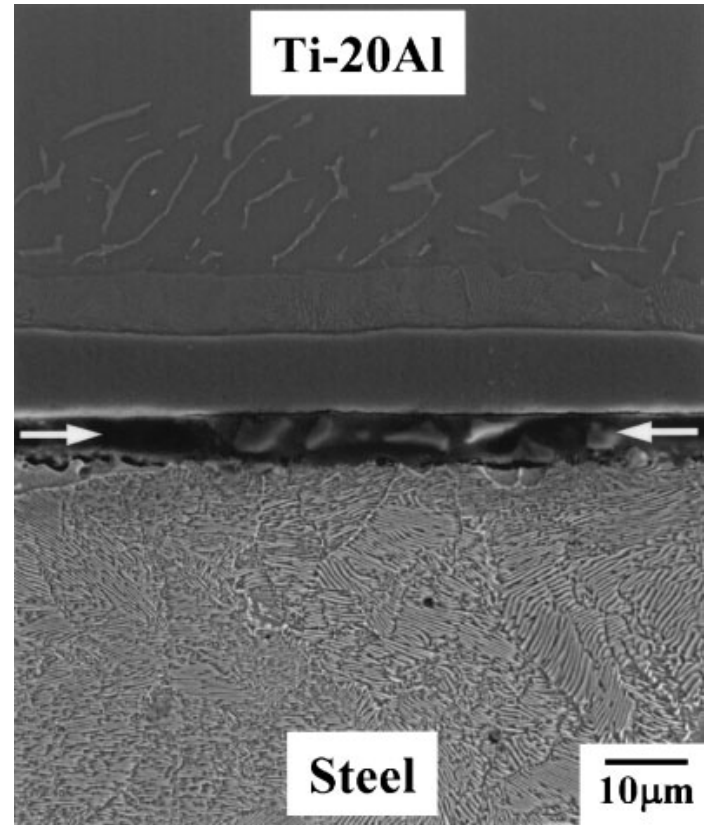

Fig. 5 SEM micrograph of the interface in Ti-20Al alloy/high carbon steel joint bonded at $1323 \mathrm{~K}$ for $0.9 \mathrm{ks}$.

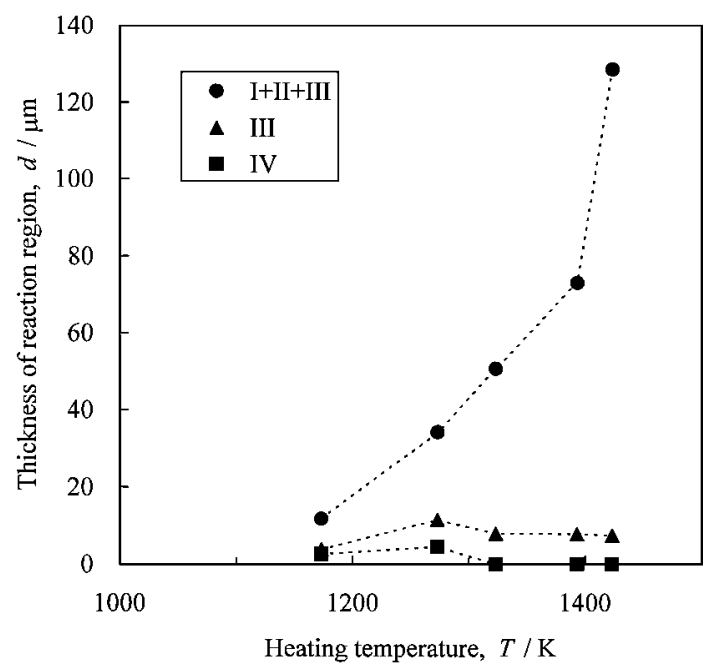

Fig. 6 Relationship between heating temperature and thickness of regions I to IV shown in Fig. 2. Ti-20Al alloy was bonded to high carbon steel at 1173 to $1423 \mathrm{~K}$ for $3.6 \mathrm{ks}$.

further developed with increasing heating temperature. Therefore, the stagnation of these growths suggests a possibility for the supply disruption of the constituent elements on the holding step in the bonding treatment. In other words, the interdiffusion at elevated temperatures is thought to be cut off by the interface separation. On the other hand, the region expressed by I + II + III grew remarkably with heating temperature. Its thickness exceeded $100 \mu \mathrm{m}$ at a heating temperature of $1423 \mathrm{~K}$. Actually, the needle-shape products were widely formed in the Ti-20Al alloy, as seen in region I in Fig. 7. However, region II, which corresponds to the reaction layer containing $\mathrm{Fe}$, could not be observed in this specimen. The composition ratio of $\mathrm{Ti}, \mathrm{Al}$ and $\mathrm{Fe}$ in the needle-shape products was $76.3: 13.5: 10.2$ (mol\%), and its Fe content was smaller than that in Table 1. The diffusion

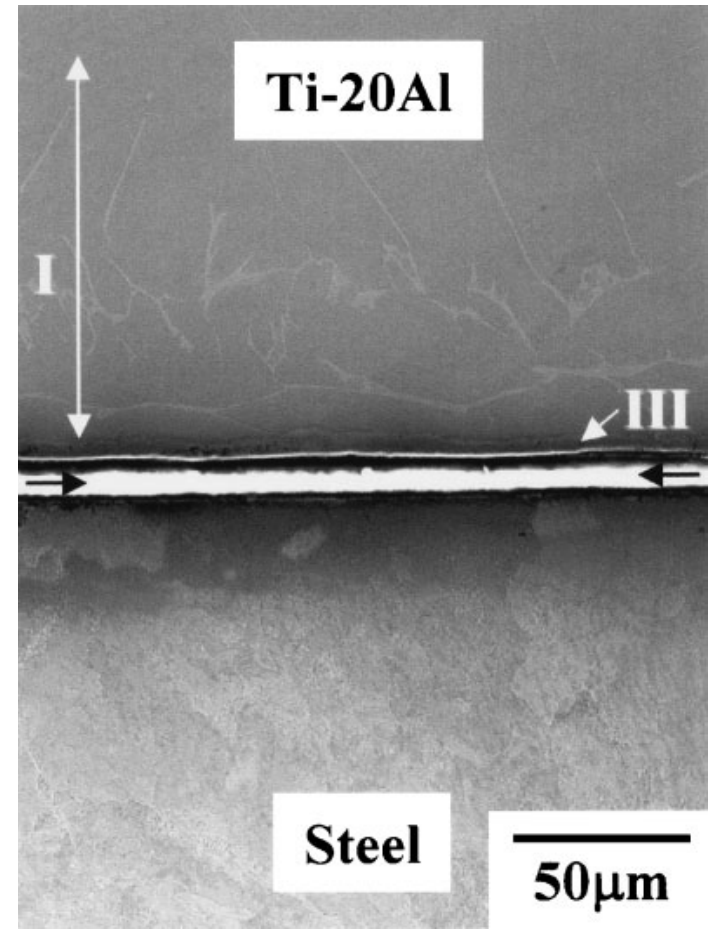

Fig. 7 SEM micrograph of the interface in Ti-20Al alloy/high carbon steel joint bonded at $1423 \mathrm{~K}$ for $3.6 \mathrm{ks}$. White region along the interface was a trace of interface separation.

of Fe on the heating step is considered as a reason for the expanding of $\mathrm{I}+\mathrm{II}+\mathrm{III}$. Since the heating rate up to $1423 \mathrm{~K}$ was $0.17 \mathrm{~K} / \mathrm{s}$, the diffusion of $\mathrm{Fe}$ into the Ti-20Al alloy should arise on the heating step. As described later, the diffusion of $\mathrm{Fe}$ is promoted with increasing heating temperature. Furthermore, Fe, which already migrates into the Ti-20Al alloy in the heating and holding steps, keeps on diffusing into the alloy even after the interface separation was induced. This appears to be responsible for the migration and the coalescence of the needle-shape products. Such a phenomenon has been also reported for $\beta$-Ti phase and Widmanstätten structure in the $\mathrm{Ti} /$ ferritic stainless steel clad. ${ }^{4)}$

According to the Ti-Al binary phase diagram in Fig. 8, ${ }^{5)}$ the Ti-20Al alloy transforms from $\alpha+\alpha_{2}$ duplex structure to $\alpha$ single phase structure at about $1273 \mathrm{~K}$. It is known that $\mathrm{Fe}$ diffuses rapidly into $\alpha$ and $\alpha_{2}$, and the diffusion coefficient of Fe into $\alpha$ is larger than that into $\alpha_{2}{ }^{6}{ }^{6}$ In addition, the diffusion of $\mathrm{Fe}$ into $\beta$-Ti is further promoted. ${ }^{7)}$ Therefore, the diffusion flux of $\mathrm{Fe}$ into the Ti-20Al alloy $\left(J^{\mathrm{Fe}} \mathrm{Ti-20 \textrm {Al }}\right)$ might increase with an increase in the heating temperature. The diffusion coefficient of Fe into $\alpha$ is $9.2 \times 10^{-14} \mathrm{~m}^{2} / \mathrm{s}$ at $1123 \mathrm{~K},{ }^{7)}$ and the value is predicted to become larger in a temperature range of more than $1273 \mathrm{~K}$. In contrast, the diffusion coefficients of $\mathrm{Ti}$ and $\mathrm{Al}$ into $\gamma$-Fe are $4.2 \times 10^{-15} \mathrm{~m}^{2} / \mathrm{s}^{7)}$ and $1.5 \times$ $10^{-15} \mathrm{~m}^{2} / \mathrm{s}^{8)}$ at $1373 \mathrm{~K}$, respectively. Ti atoms also contribute to the formation of the thermodynamically stable TiC layer at the interface. Consequently, the diffusion flux of $\mathrm{Ti}$ and $\mathrm{Al}$ into the steel at more than $1273 \mathrm{~K}$ is considerably smaller than $J^{\mathrm{Fe}}{ }_{\mathrm{Ti}-20 \mathrm{Al}}$. In other words, Fe atoms in the steel migrate unilaterally into the Ti-20Al alloy. The formation and accumulation of voids resulting from such a unilateral 


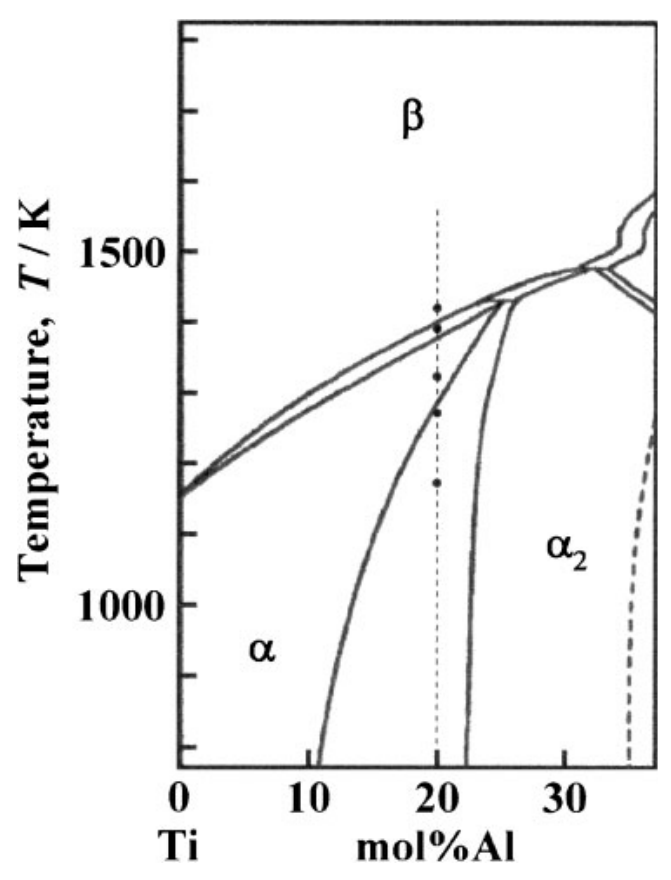

Fig. 8 Phase diagram of Ti-Al system.

diffusion is considered as a cause of the interface separation. The voids may be regarded as a kind of Kirkendall void, though fast diffusion mechanism of $\mathrm{Fe}$ into $\mathrm{Ti}$ materials and the position of initial interface should be taken into account.

\subsection{Water-quenching from $1273 \mathrm{~K}$}

There is a possibility that the interface separation induced in the Ti-20Al alloy/high carbon steel joint is attributed to the interdiffusion across the interface. To prove this assumption, the direct observation of interfacial aspect at elevated temperatures is desired, but it is difficult. For this reason, the joint bonded at $1173 \mathrm{~K}$ was quenched into the water from a temperature of $1273 \mathrm{~K}$. The specimen with a special shape shown in Fig. 1(b) was prepared to avoid the occurrence of cracks at the interface in the quenching operation. High carbon steel powders in the copper pipe have a role to coat the joint by sintering at $1273 \mathrm{~K}$. The holding time was $0.9 \mathrm{ks}$ at $1273 \mathrm{~K}$. Figure 9(a) shows a cross-sectional view of the specimen after quenching. There were no cracks caused by quenching and the shape of the joint was retained. An enlarged optical micrograph of the central area in this specimen was presented in Fig. 9(b).
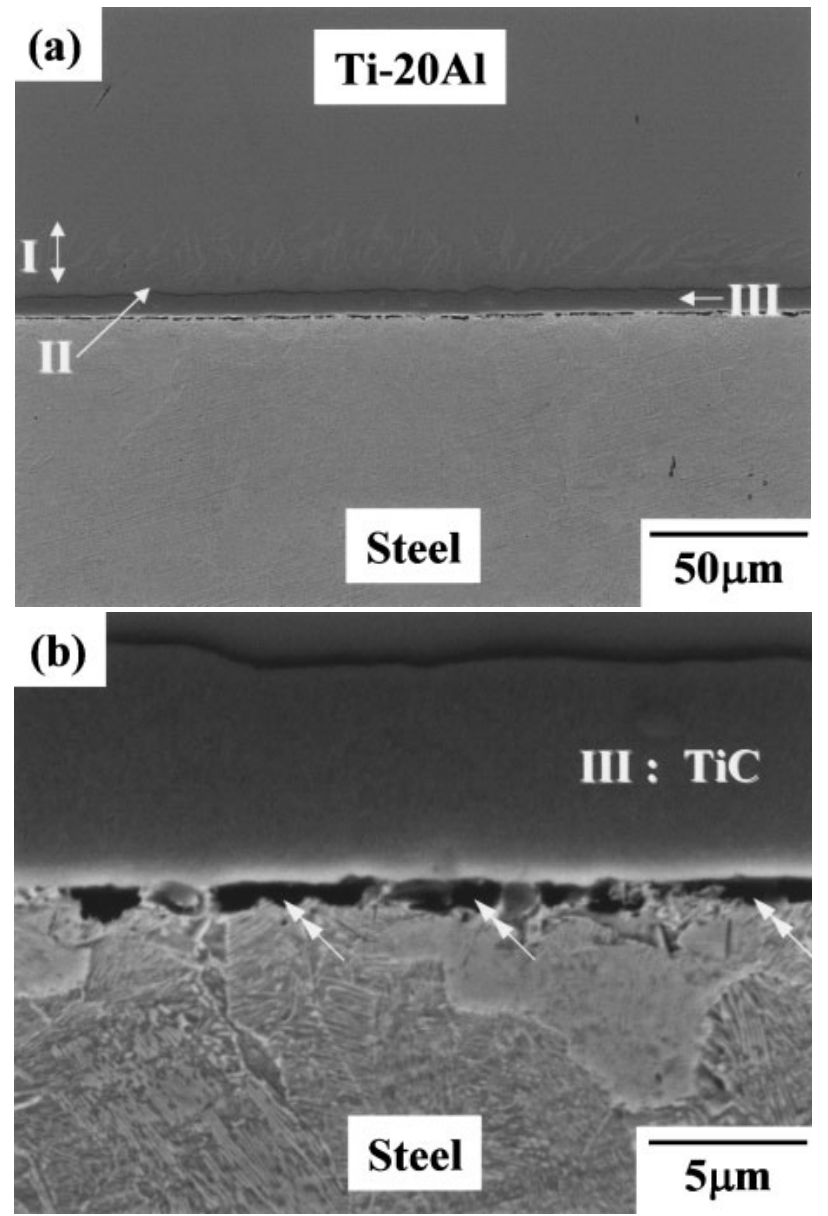

Fig. 10 (a) SEM micrograph of the interface in Ti-20Al alloy/high carbon steel joint after quenching into the water from $1273 \mathrm{~K}$. (b) Enlarged SEM micrograph of the interface in (a).

It seems that the cooling rate was somewhat reduced by the existence of the copper pipe and the evacuated silica tube, since the steel did not show a martensitic structure. However, the steel showed a Vickers hardness of about 400, and this value was higher than that in the joint cooled in the furnace $(\mathrm{Hv}=$ about 250$)$. Figure 10 shows SEM micrographs of the interface in the joint after quenching. The joint had the reaction products indicated by I and II, which were formed by the diffusion of Fe into the Ti-20Al alloy, and the TiC layer indicated by III in the vicinity of the interface. The voids indicated by double arrows were also formed between the steel and the TiC layer. This aspect is similar to
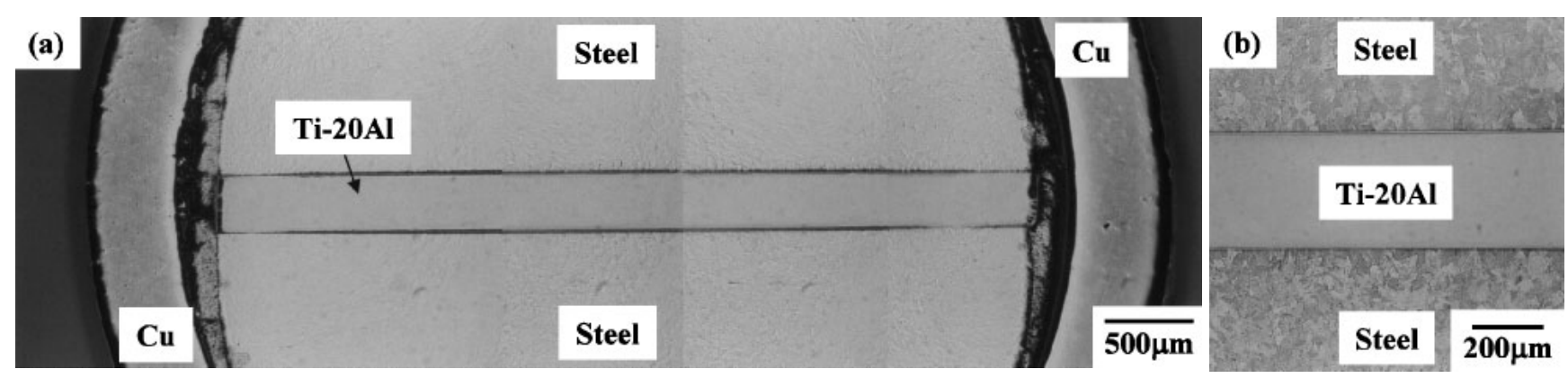

Fig. 9 (a) Cross-sectional view of Ti-20Al alloy/high carbon steel joint after quenching into the water from $1273 \mathrm{~K}$. (b) Optical micrograph of the interface in (a). 
that in Fig. 4(a). Although the influence of polishing and etching for microstructure observations is not negligible, many voids are considered to be generated by the heat treatment at $1273 \mathrm{~K}$ as compared to Fig. 2(b). This suggests that the interface separation occurs in the holding step at elevated temperatures. Therefore, it is thought that the diffusion of constituent elements across the interface is responsible for this phenomenon.

The interface separation phenomenon related to the interdiffusion has not been reported to the best of our knowledge. The further investigation is necessary with the inclusion of its industrial application.

\section{Conclusions}

Ti-20Al alloy was diffusion-bonded to high carbon steel in the range from 1173 to $1423 \mathrm{~K}$ for 0.9 to $3.6 \mathrm{ks}$ in a vacuum to investigate the mechanism of interface separation phenomenon. Several joints were heated at $1173 \mathrm{~K}$ for up to $176.4 \mathrm{ks}$ in an evacuated silica tube. The main conclusions are summarized as follows.

(1) In the joint bonded at $1173 \mathrm{~K}$, the interface separation did not occur even after prolonged heat treatment. The joint had four kinds of reaction regions in the vicinity of the interface, and these grew in proportion to square root of holding time. (2) The joint bonded at more than $1273 \mathrm{~K}$ showed the separation at the interface. The holding time to induce this phenomenon became shorter, as the heating temperature increased. Since the thickness of $\mathrm{TiC}$ and ferrite layers formed at the interface hardly changed with an increase in the heating temperature, it is thought that the supply of constituent elements is inhibited on the holding step in the bonding treatment. In other words, the interface separation is responsible for such a supply disruption.

(3) The joint was quenched into the water from $1273 \mathrm{~K}$ to investigate the interfacial microstructures at high-temperature state. The formation of voids was confirmed between the steel and the TiC layer. This suggests that the interface separation occurs in the holding step at $1273 \mathrm{~K}$. This also gives support to the relation between this phenomenon and interdiffusion.

\section{Acknowledgements}

The present study was supported by the ISIJ Research Promotion Grant of The Iron and Steel Institute of Japan, and we greatly appreciate their support.

\section{REFERENCES}

1) Y. Morizono, M. Nishida, A. Chiba, T. Yamamuro, Y. Kanamori and T. Terai: Mater. Trans. 45 (2004) 527-531.

2) Y. Morizono, T. Yamamuro and M. Nishida: Mater. Trans. 48 (2007) 1476-1482.

3) Y. Morizono, Y. Kodama, T. Yamamuro and M. Nishida: Tetsu-toHagane 94 (2008) 251-257.

4) Y. Morizono, M. Nishida, A. Chiba and K. Imamura: Tetsu-to-Hagane 85 (1999) 340-345.

5) R. Kainuma, M. Palm and G. Inden: Intermetallics 2 (1994) 321-332.

6) Y. Mishin and C. Herzig: Acta Mater. 48 (2000) 589-623.

7) Metals Data Book, ed. by Japan Inst. Metals (Maruzen Co., Ltd. 1993) pp. 20-25.

8) O. Taguchi, M. Hagiwara, Y. Yamazaki and Y. Iijima: Defect Diffusion Forum 194-199 (2001) 91-96. 